\title{
Diet and risk of oral potentially malignant disorders in rural Sri Lanka
}

\author{
Hemantha K. Amarasinghe ${ }^{1}$, Udaya Usgodaarachchi' ${ }^{2}$, Menaka Kumaraarachchi ${ }^{3}$, Newell Johnson ${ }^{4}$, \\ Saman Warnakulasuriya $\mathbf{a}^{5,6}$ \\ ${ }^{1}$ National Cancer Control Programme, Colombo 05, Sri Lanka; ${ }^{2}$ Family Health Bureau, Colombo 05, Sri Lanka; ${ }^{3}$ Oral Health Institute, \\ Maharagama, Sri Lanka; ${ }^{4}$ Griffith Health Institute, Gold Coast Campus, Griffith University, Gold Coast, Qld, Australia; ${ }^{5}$ Oral Medicine, \\ $\mathbf{2 , 3}$ King's College, London, UK; ${ }^{6}$ WHO collaborating centre for Oral Cancer, ????, ????
}

\begin{abstract}
BACKGROUND: While protective role of antioxidant nutrients against cancer is well established, data on Asian diets in patients with oral cancer are meagre.

METHODS: A total of 1029 subjects over 30 years of age were investigated on their dietary practices in the Sabaragamuwa province in 2006-07. Data collection tools were an interviewer-administered questionnaire, a threeday food diary and an examination of the oral cavity. Subjects identified with Oral Potentially Malignant Disorders (OPMD) and disease-free controls were analysed in a case-control fashion. Among the OPMDs, those with leukoplakia were separately considered. A further subgroup analysis was undertaken for $\beta$-carotene-rich foods. The analysis was stratified by portions of fruit/vegetables consumed as five or more portions and two or more portions daily.
\end{abstract}

RESULTS: A low BMI $(<18.5)$ was a significant independent risk factor for the development of OPMD. More than half of both cases and controls consumed less than two portions of fruit/vegetables per day and only 20 subjects consumed more than five portions per day. Intake of more than two portions per day of $\beta$-carotenecontaining fruits/vegetables significantly reduced the risk of having an OPMD and leukoplakia $(O R=0.5 ; 95 \% \mathrm{CI}$, 0.3-0.9). The significant differences observed with BMI and fruits/vegetables were attenuated when adjusted for betel quid chewing, smoking and alcohol use.

CONCLUSIONS: This study discloses prevailing undernutrition in this rural population with very low daily consumption of fruit/vegetables. Cancer preventive properties in their diets are limited and are swamped by the known carcinogenic agents associated with use of betel quid, tobacco and alcohol.

J Oral Pathol Med (2013)

Correspondence: Hemantha K. Amarasinghe, National Cancer Control Programme, Colombo 05, Sri Lanka. Tel: Xxxx, Fax: Xxxx, E-mail:

4 hemanthaamarasinghe@yahoo.com

Accepted for publication March 15, 2013
Keywords: BMI; fruit and vegetables; oral cancer; oral potentially malignant disorders; risk factors; Sri Lanka; $\beta$-carotene

\section{Introduction}

Squamous cell carcinoma of the oral cavity is often preceded by oral potentially malignant disorders (OPMD), the term recommended by the WHO Collaborating Centre for Oral Cancer/Precancer to encompass what were earlier referred to as 'precancer' or 'premalignant lesions and conditions'(1). In this study, we considered oral leukoplakia, oral submucous fibrosis (OSF), erythroplakia and lichen planus as part of the spectrum of OPMD. The global $\mathbf{5}$ prevalence of OPMD has been reported at between 1 and $5 \%$ (2), but higher prevalences are described from South and South-East Asia, with male preponderance: for example, Taiwan (12.7\%) (3); and in some Western Pacific countries, for example, Papua New Guinea, $11.7 \%$ (4). Such wide geographical variations are due to lifestyles specific to the country or region. In a screening programme undertaken in Sri Lanka, the prevalence of oral precancer in the 1980s was reported as $4.2 \%(5)$.

Dietary factors are estimated to account for approximately $30 \%$ of cancers in Western countries (6). This proportion is currently thought to be about $20 \%$ in developing countries and is projected to increase in the future (7). Studies have revealed that a diet low in fresh fruits and vegetables is a significant risk factor for oral cancer in young subjects in the UK (8) and for OPMD in Japanese subjects living in the UK (9). A case-control study undertaken, with data from an ongoing randomized oral cancer screening trial in Kerala, India yielded an inverse dose-response relationship between BMI and risk of leukoplakia ( $P$ for trend $=0.007$ ) $(10)$.

Evidence for the bio-protective effect of the diet comes from case-control and cohort studies, from animal and from in vitro experiments. The micronutrients in food which confer these benefits are also well understood. Vitamin A and related carotenoids (in particular $\beta$-carotene), vitamin $\mathrm{C}$ 
and selenium appear to be particularly protective against most epithelial cancers and their precursor lesions (11-14), and much of the effect is attributable to their antioxidant activities. Antioxidants act by reducing free radical reactions that can cause DNA mutations and changes in lipid peroxidation of cellular membranes $(15,16)$. Other protective roles of micronutrients are modulation of carcinogen metabolism, maintenance of appropriate cell differentiation, inhibition of cell proliferation and oncogene expression, maintenance of immune function and inhibition of formation of endogenous carcinogens (17).

A recent meta-analysis on risk factors for oral cancer, based on 15 case-control studies and one cohort study, was able to utilize diet data from nearly 5000 subjects: this estimated that each portion of fruit or vegetables consumed per day reduced the risk of oral cancer by around $50 \%$ (18). These effects are also demonstrable with OPMD: in a population-based case-control study in Japan, serum levels of lycopene and beta-carotene were significantly lower in those with leukoplakia; logistic regression of their data showed that high levels of $\beta$-carotene were related to low risk of oral leukoplakia $(\mathrm{OR}=0.16 \% \mathrm{CI}$ : 0.03-0.86) (19).

Intervention studies are also encouraging in this respect. In a double-blind placebo controlled trial in Kerala, India (14), up to one-third of subjects showed regression of their oral leukoplakias after 12 months supplementation with oral $\beta$-carotene. An open-ended trial with multiple micronutrient supplementation over one to 3 years improved the symptomatology of 117 oral submucous fibrosis (OSF) patients in Pakistan (20).

Tea has strong protective effects against many cancers. Most research has examined green tea (21-23), but black tea is also protective (24-27). It is predominantly the polyphenols present in tea that act as antioxidants to counteract both initiation and promotion of carcinogenesis (15).

The role of chillies in the diet in either promoting oral carcinogenesis or providing protection against oral cancer has not been examined in detail. The phytochemicals in spices, including chillies, have potent antioxidant and enzyme activities, which have the potential to reduce the risk of cancer through several complementary and overlapping mechanisms (28).

Due to the paucity of studies on dietary factors and OPMD in Sri Lanka, we investigated the association of OPMD (and leukoplakia as a subgroup) with consumption of fruits, vegetables, chillies and tea.

\section{Materials and methods}

A cross-sectional community survey, employing a house-tohouse method to interview and perform a visual screening for OPMD, was conducted in the Sabaragamuwa province. A total of 1029 subjects were selected by a multistage, stratified and clustered sampling technique. We have described the study population in detail elsewhere: approximately $87 \%$ lived in small villages and were employed in farming; around 9\% lived and worked on tea and rubber estates $(29,30)$. Ethical approval was obtained from the Faculty of Medicine, University of Colombo, and subjects signed for their informed consent before data collection.
An interviewer-administered questionnaire collected the socio-demographic variables of age, gender, ethnicity, occupation and level of education. Lifestyle questions covered betel quid chewing, smoking and use of alcoholic beverages, defined as those who had never, or ever, practised a habit. 'Ever' habits were further subdivided into past, occasional and weekly/daily $(31,32)$. Weight and height of subjects were measured to calculate BMI.

Consumption of fruit, vegetables and tea was measured with a three-day diet diary for 2 days in the week and 1 day on the weekend, prior to the oral examinations. Participants were instructed to write the items and amount consumed according to common household utensil units (e.g. 'tablespoonful') without changing their food consumption pattern.

From November 2006 to November 2007, the first author examined the oral cavities of all 1029 subjects above the age of 30 years, blinded to their risk factor status at the time of examination. The diagnostic criteria for the detection of OPMD: leukoplakia and erythroplakia were based on WHO criteria; and for OSF, lichen planus and other oral mucosal abnormalities, on criteria used for previous screening programmes $(1,33,34)$. Oral verrucous hyperplasia although considered an entity in the OPMD group (particularly in Taiwan) is not encountered in Sri Lanka and is therefore not included in our study $(3,35)$. Chewer's mucosa, quid-induced lichenoid reactions, smoker's keratosis, denture stomatitis, angular cheilitis and pallor and depapillation of tongue were considered as 'other' oral mucosal abnormalities. Definitions of these conditions and descriptions of sampling and data collection methods are described elsewhere (29).

The subjects identified with OPMD during this crosssectional study were analysed in a case-control fashion to assess strength of the association between diet and OPMD. The main subgroup of OPMDs, that is, oral leukoplakia cases was separately analysed. 'Controls' were selected from subjects free of any oral mucosal disorders at the time of screening.

\section{Statistical analysis}

Data were recorded on paper, using the pre-tested questionnaire (available on request from principal author), and entered into the SPSS 17 software package, which was used for all statistical analyses. The relationships between two categorical variables were tested by chi-square. Correspondence analysis was used to combine information on occupation and education to produce a single score for SES, on a continuous scale, for each subject (36). Consumed fruit and vegetables were later quantified into portions (37): 3-4 spoonfuls of cooked vegetable, 10 spoonfuls of uncooked/raw vegetable, one medium-sized banana, orange and apple, 9-11 grapes or similar fruits, onefourth of medium size pawpaw, a one half avocado and $100 \mathrm{ml}$ cup of undiluted fruit juice were considered as single portions (Fig. 1). A tea cup was defined as the $100 \mathrm{ml}$ vessel shown in Fig. 1.

The fruits and vegetables consumed were then classified based on national guidelines according to the content of $\beta$-carotene in each item. Food items that do not contain betacarotene, according to the Hector Kobbakaduwa Agriculture Research Centre, were counted separately (38). 


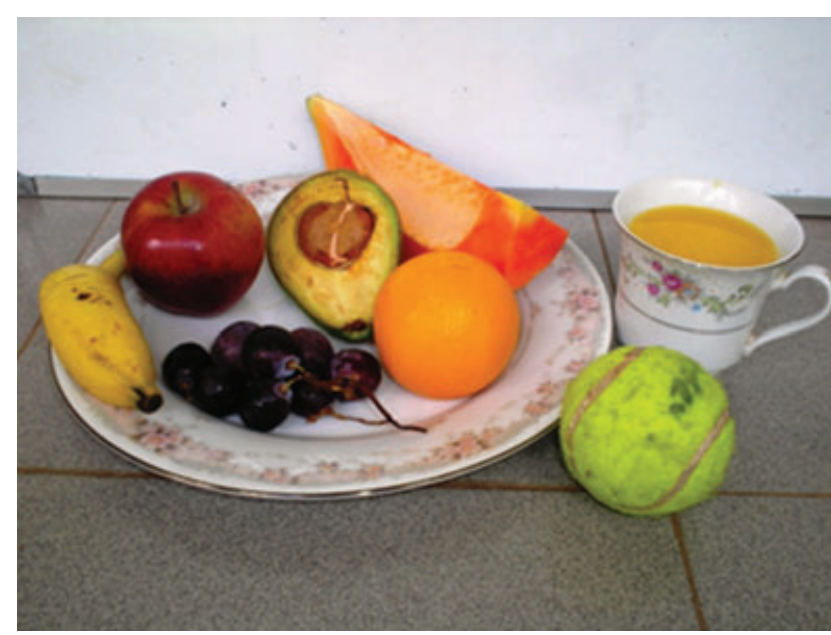

Figure 1 Portion sizes of different fruit items.

Once food items were identified, the weighted daily average intake of each category of food portions consumed was calculated using the following formula (39):

Average intake of fruit and vegetable portion

$$
=\frac{[(5 \times 2 \text { working days } / 2) \pm(\text { Saturday or Sunday }) \times 2]}{7}
$$

The strength of association between a given food and clinical disease was tested in a case-control fashion. Bivariate analysis was carried out to assess the strength of the association, and a logistic regression model was used to define the effects of controlling potentially confounding variables. All other potential confounding variables were included as covariates. Of these, age, BMI- and $\beta$-carotenecontaining vegetable and fruit portions were entered as continuous variables, the remainder as categorical variables. An enter-method conditional approach was used with p-values less than 0.05 considered statistically significant.

A subgroup analysis was carried out separately to explore the protective effect of fruit and vegetables for leukoplakia as a dependent variable and collectively as OPMD. This analysis took into account two portions and five portions of fruit and vegetables consumed per day as cut-off values.

\section{Results}

Among the 1029 subjects screened, 102 cases of OPMD were detected. Among OPMD: leukoplakia was most common $71(8.9 \%)$, with OSF second $25(1.7 \%)$ and the remainder of cases were lichen planus $6(0.7 \%)$. In addition, there were four cases of oral cancer, one newly diagnosed and three under treatment and one case of treated leukoplakia: these were excluded from the analysis. One hundred and ninety-five subjects diagnosed with other oral mucosal diseases were excluded, leaving 728 healthy subjects designated as controls for the case-control analysis. When weighted for age and place of residence - namely village or Estate - this represents a prevalence of $11.3 \%$ for OPMD (32). Of the 1029 subjects, 914 completed the food diary, a response rate of $89 \%$.
In the present study, perusal of the food diaries revealed diets to be rich in starchy vegetables such as jack fruit, breadfruit and yams. Large quantities of these were consumed. More than $50 \%$ of both cases and controls consumed less than 2 portions of fruit and vegetables per day. The WHO recommended consuming 5 portions as a guideline, but in our study, only 20 subjects consumed more than 5 portions per day; $99 \%$ of the cases and $97 \%$ of the controls consumed less than 5 portions of fruit and vegetable per day.

Table 1 shows the association of OPMD with total vegetable and fruit portions consumed per day and with BMI. In $42 \%$ of the cases and $30.6 \%$ of the controls, the BMI was less than 18.5 . Only $14.7 \%$ of the study subjects were in overweight and obese (BMI $>25)$ categories. ORs were reduced with normal weight (BMI 18.5-25) and overweight/obese categories (BMI $>25)$ compared with those of BMI $<8.5$. This was not significant when adjusted for other confounding factors: betel quid chewing, smoking, alcohol use and socio-demographic factors such as age, sex, education and occupation. As shown in Table 1, no association was observed for consumption of total vegetable and fruit portions per day at either 2 portions and 5 portions as cut-off values.

Intake of $\beta$-carotene-containing vegetables and fruit portions and risk of occurrence of OPMD was not statistically significant when considered as 5 portions of fruits and vegetables. The combined effect of consuming more than 2 portions per day of $\beta$-carotene-containing vegetables plus fruit portions have shown crude OR of 0.5 ; 95\% CI, 0.3-0.9. However, the logistic regression analysis shows an attenuation of the protective effect of betacarotene-rich vegetables and fruits when controlling for other covariates, the adjusted OR being 0.8 (CI 0.4-1.4) (Table 1).

Table 2 shows the risk of occurrence of leukoplakia with total vegetable and fruit portions consumed per day and with BMI. In $37 \%$ of the cases and $30.6 \%$ of the controls, the BMI was less than 18.5 . Only $15 \%$ of the study subjects were in overweight and obese (BMI $>25)$ categories. ORs were reduced with normal weight (BMI 18.5-25) and overweight/obese categories (BMI $>25)$ compared with those of BMI $<18.5$, but it was not significant.

No association was observed for risk of occurrence of leukoplakia and consumption of total vegetable and fruit portions per day when separately considering either two portions or five portions as cut-off values.

Intake of $\beta$-carotene-containing vegetables and fruit portions and risk of occurrence of leukoplakia was not statistically significant in the group consuming 5 portions of fruits and vegetables compared with the rest. The combined effect of consuming more than 2 portions per day of $\beta$ carotene-containing vegetables plus fruit portions have shown crude OR of $0.5 ; 95 \%$ CI, 0.3-0.9. However, on logistic regression analysis an attenuation of the protective effect of beta-carotene-rich vegetables and fruits was noted when controlling for other covariates, the adjusted OR being 0.8 (CI 0.4-1.7) (Table 2).

Table 3 illustrates the association between OPMD and the number of cups of tea consumed per day, and with chillie consumption. More than two cups of tea were 
Table 1 Risk of occurrence of OPMD and BMI, consumption of total fruits/Vegetables and $\beta$-carotene containing fruit/vegetable portions per day

\begin{tabular}{|c|c|c|c|c|c|}
\hline Characteristics & $\begin{array}{c}\text { OPMD Cases } \\
(\mathrm{n}=101) \mathrm{n}(\%)\end{array}$ & $\begin{array}{c}\text { Controls } \\
(\mathrm{n}=728) \mathrm{n}(\%)\end{array}$ & $\mathrm{P}$-value & $\begin{array}{c}\text { Crude OR } \\
( \pm 95 \% \text { CI })\end{array}$ & $\begin{array}{r}\text { Adjusted }^{a} \text { OR } \\
( \pm 95 \%\end{array}$ \\
\hline \multicolumn{6}{|l|}{ BMI } \\
\hline $0-18.5$ & $42(41.6)$ & $221(30.6)$ & & 1.0 & 1.0 \\
\hline$>18.5-25$ & $50(49.5)$ & $389(53.9)$ & 0.08 & $0.7(0.4-1.0)$ & $0.8(0.5-1.3)$ \\
\hline$>25$ & $9(8.9)$ & $112(15.5)$ & 0.02 & $0.4(0.2-0.9)$ & $0.8(0.4-1.9)$ \\
\hline Missing & & 6 & & & \\
\hline \multicolumn{6}{|c|}{ Total fruit and vegetable portions per day } \\
\hline$<5$ portions & $94(98.9)$ & $622(97.0)$ & & 1.0 & \\
\hline$>5$ portions & $1(1.1)$ & $19(3.0)$ & 0.307 & $0.3(0.0-2.6)$ & $1.4(0.7-2.6)$ \\
\hline Missing & 6 & 87 & & & \\
\hline \multicolumn{6}{|c|}{ Total fruit and vegetable portions per day } \\
\hline$<2$ portion & $61(64.2)$ & $335(52.3)$ & & 1.0 & 1.0 \\
\hline$>2$ portions & $34(35.8)$ & $306(47.7)$ & 0.03 & $0.6(0.4-0.9)$ & $1.1(0.6-1.8)$ \\
\hline Missing & 6 & 87 & & & \\
\hline \multicolumn{6}{|c|}{$\beta$-carotene containing fruit and vegetable portions per day } \\
\hline$<5$ portion & $95(100.0)$ & $628(98.0)$ & & 1.0 & 1.0 \\
\hline$>5$ portions & 0 & $13(2)$ & 0.30 & $0.5(0.0-3.9)$ & 0.000 \\
\hline Missing & 6 & 87 & & & \\
\hline \multicolumn{6}{|c|}{$\beta$-carotene containing fruit and vegetable portion per day } \\
\hline$<2$ portion & $75(78.9)$ & $424(66.1)$ & & 1.0 & 1.0 \\
\hline$>2$ portions & $20(21.1)$ & $217(33.9)$ & 0.01 & $0.5(0.3-0.8)$ & $0.8(0.4-1.4)$ \\
\hline Missing & 6 & 87 & & & \\
\hline Total & $101(100.0)$ & $728(100.0)$ & & & \\
\hline
\end{tabular}

${ }^{\mathrm{a} O R}$ adjusted for sex, age, occupation, education, BMI, smoking, betel chewing and alcohol drinking.

Table 2 Risk of occurrence of leukoplakia and BMI, consumption of total fruits/Vegetables and $\beta$-carotene containing fruit/vegetable portions per day

\begin{tabular}{|c|c|c|c|c|c|}
\hline Characteristics & $\begin{array}{c}\text { Leukoplakia } \\
(\mathrm{n}=70) \mathrm{n}(\%)\end{array}$ & $\begin{array}{c}\text { Controls } \\
(\mathrm{n}=728) \mathrm{n}(\%)\end{array}$ & P-value & $\begin{array}{c}\text { Crude OR } \\
( \pm 95 \% \text { CI })\end{array}$ & $\begin{array}{r}\text { Adjusted }^{a} \text { OR } \\
( \pm 95 \% \text { CI })\end{array}$ \\
\hline \multicolumn{6}{|l|}{ BMI } \\
\hline $0-18.5$ & $26(37.1)$ & $221(30.6)$ & & 1.0 & 1.0 \\
\hline$>18.5-25$ & $36(54.1)$ & $389(53.9)$ & 0.37 & $0.7(0.4-1.3)$ & $1.0(0.6-1.9)$ \\
\hline$>25$ & 8 (11.4) & $112(15.5)$ & 0.23 & $0.6(0.2-1.4)$ & $1.4(0.6-3.6)$ \\
\hline \multicolumn{6}{|c|}{ Total fruit and vegetable portion per day } \\
\hline$<5$ portions & $65(98.5)$ & $622(97.0)$ & & 1.0 & \\
\hline$>5$ portions & $1(1.5)$ & $19(3.0)$ & 0.507 & $0.5(0.0-3.8)$ & $0.8(0.0-8.2)$ \\
\hline Missing & 4 & 87 & & & \\
\hline \multicolumn{6}{|c|}{ Total fruit and vegetable portions per day } \\
\hline$<2$ portion & 42 (63.6.) & $335(52.3)$ & & 1.0 & 1.0 \\
\hline$>2$ portions & $24(36.4)$ & $306(47.7)$ & 0.08 & $0.6(0.4-1.0)$ & $1.1(0.6-2.1)$ \\
\hline Missing & 4 & 87 & & & \\
\hline \multicolumn{6}{|c|}{$\beta$-carotene containing fruit and vegetable portions/day } \\
\hline$<5$ portions & $66(100.0)$ & $628(98.0)$ & & 1.0 & 1.0 \\
\hline$>5$ portions & 0 & $13(2)$ & 0.76 & $0.7(0.1-5.6)$ & 0.000 \\
\hline Missing & 4 & 87 & & & \\
\hline \multicolumn{6}{|c|}{$\beta$-carotene containing fruit and vegetable portions/day } \\
\hline$<2$ portion & $52(78.8)$ & $424(66.1)$ & & 1.0 & 1.0 \\
\hline$>2$ portions & $14(21.2)$ & $217(33.9)$ & 0.04 & $0.5(0.3-0.9)$ & $0.8(0.4-1.7)$ \\
\hline Missing & 4 & 87 & & & \\
\hline Total & $70(100.0)$ & $728(100.0)$ & & & \\
\hline
\end{tabular}

${ }^{\mathrm{a}} \mathrm{OR}$ adjusted for sex, age, occupation, education, BMI, smoking, betel chewing and alcohol drinking.

consumed per day by $30 \%$ of the cases, and by $28 \%$ of the controls: these differences were not statistically significant. Twenty-four per cent of the cases consumed high amounts of chillie and $66 \%$ of cases consumed medium amounts of chillie with meals. The controls reported similar patterns of chillie consumption.

Table 4 shows a statistically significant association between alcohol drinking and low consumption of fruits and vegetables. The majority ( $80 \%)$ of weekly drinkers were consuming less than two portions of 'beta-carotene-high vegetable and fruit portions' per day. Perusal of the food diaries of chronic heavy alcohol users revealed that most frequently missed dinner altogether. Half of the regular alcohol drinkers were taking only one cup of tea per day.

The final logistic regression model has shown, betel quid chewing and alcohol consumption are the only statistically significant characteristics remained after controlling the other factors which were already published in 2009 (30). 
Table 3 Association between OPMD and consumption pattern of tea and chillies

\begin{tabular}{|c|c|c|c|c|c|}
\hline Characteristics & $\begin{array}{c}\text { OPMD Cases } \\
(\mathrm{n}=101) \mathrm{n}(\%)\end{array}$ & $\begin{array}{c}\text { Controls } \\
(\mathrm{n}=728) \mathrm{n}(\%)\end{array}$ & $\mathrm{P}$-value & $\begin{array}{c}\text { Crude OR } \\
( \pm 95 \% \text { CI })\end{array}$ & $\begin{array}{c}\text { Adjusted }^{a} \text { OR } \\
( \pm 95 \% \\
( \pm I)\end{array}$ \\
\hline \multicolumn{6}{|c|}{ Consumption of tea, cups } \\
\hline$\leq 1$ per day & $36(37.9)$ & $252(39.9)$ & & 1.0 & 1.0 \\
\hline$>1$ to $\leq 2$ per day & $30(31.6)$ & $203(32.1)$ & 0.898 & $1.0(0.6-1.7)$ & $1.4(0.8-2.4)$ \\
\hline$>2$ per day & $29(30.5)$ & $177(28.0)$ & 0.609 & $1.1(0.7-1.9)$ & $1.3(0.7-2.4)$ \\
\hline Missing & 6 & 96 & & & \\
\hline \multicolumn{6}{|c|}{ Temperature of tea consumption } \\
\hline Lukewarm & $12(12.0)$ & $57(7.9)$ & & 1.0 & 1.0 \\
\hline Mildly hot & $68(68.0)$ & $520(72.1)$ & 0.165 & $0.6(0.3-1.2)$ & $0.8(0.4-1.6)$ \\
\hline Hot & $20(20.0)$ & $144(20.0)$ & 0.295 & $0.6(0.3-1.4)$ & $0.8(0.3-1.8)$ \\
\hline Missing & 1 & 7 & & & \\
\hline \multicolumn{6}{|l|}{ Chillie consumption } \\
\hline Low & $10(10.0)$ & $38(5.2)$ & & $1.0 \bigcirc 2=$ & 1.0 \\
\hline Medium & $66(66.0)$ & $506(69.9)$ & 0.064 & $0.5(0.2-1.0)$ & $0.7(0.3-1.4)$ \\
\hline High & $24(24.0)$ & $180(24.9)$ & 0.103 & $0.5(0.2-1.1)$ & $0.6(0.4-1.5)$ \\
\hline Missing & 1 & 4 & & $x^{2}+2$ & \\
\hline Total & $101(100.0)$ & $728(100.0)$ & & & \\
\hline
\end{tabular}

${ }^{a}$ OR adjusted for sex, age, occupation, education, BMI, smoking, betel chewing and alcohol drinking.

Use of betel quid shows a strong dose-response relationship. The adjusted OR for daily chewers was 10.6 (95\% CI, 3.6-31.0) after controlling for all other variables.

Regular alcohol drinking was associated with an increased risk of OPMD, the adjusted OR for weekly drinkers being 3.5 (1.6-8.0).

\section{Discussion}

In the published literature, there is convincing evidence that high intake of fruit and vegetables decreases the risk of cancers of the mouth and pharynx, oesophagus, lung, stomach, colon and rectum $(40,41)$ and their precursor lesions (20, 42). Micronutrients such as vitamins A, C, E and carotenoids (in particular $\beta$-carotene and lycopene)

Table 4 Distribution of subjects according to weekly consumption of alcohol

\begin{tabular}{|c|c|c|c|c|}
\hline \multirow[b]{2}{*}{ Characteristics } & \multicolumn{3}{|c|}{ Alcohol consumers } & \multirow[b]{2}{*}{ P-value } \\
\hline & $\begin{array}{l}\text { Never } \\
\mathrm{n}(\%)\end{array}$ & $\begin{array}{l}\text { Weekly } \\
\mathrm{n}(\%)\end{array}$ & $\begin{array}{l}\text { Total } \\
\mathrm{n}(\%)\end{array}$ & \\
\hline \multicolumn{5}{|c|}{$\beta$-carotene containing vegetable portions per day } \\
\hline$<1$ portion & $153(28.8)$ & $35(42.2)$ & $188(30.6)$ & \multirow{4}{*}{$\begin{array}{c}0.006 \\
\left(\chi_{2}^{2}=10.3\right)\end{array}$} \\
\hline $\begin{array}{l}>1 \text { to } \leq 2 \\
\text { portions }\end{array}$ & $187(35.2)$ & $32(38.6)$ & $219(35.7)$ & \\
\hline$>2$ portions & $191(36.0)$ & $16(19.3)$ & $207(33.7)$ & \\
\hline Missing & 59 & 15 & 74 & \\
\hline \multicolumn{5}{|c|}{ Total fruit \& vegetable portions per day } \\
\hline$\leq 1$ portion & $96(18.1)$ & $30(36.1)$ & $126(20.5)$ & \multirow{4}{*}{$\begin{array}{c}<0.001 \\
\left(\chi_{2}^{2}=10.3\right)\end{array}$} \\
\hline $\begin{array}{l}>1 \text { to } \leq 2 \\
\text { portions }\end{array}$ & $162(30.5)$ & $30(36.1)$ & $192(31.3)$ & \\
\hline$>2$ portions & $273(51.4)$ & $23(27.7)$ & $296(48.2)$ & \\
\hline Missing & 59 & 15 & 74 & \\
\hline \multicolumn{5}{|c|}{ Consumption of tea: cups per day } \\
\hline$<1$ per day & $198(37.9)$ & $40(48.8)$ & 238 (39.3) & \multirow{5}{*}{$\begin{array}{c}0.154 \\
\left(\chi_{2}^{2}=10.3\right)\end{array}$} \\
\hline $\begin{array}{l}>1 \text { to } \leq 2 \\
\text { per day }\end{array}$ & $173(33.1)$ & $24(29.3)$ & 197 (32.6) & \\
\hline$>2$ per day & $152(29.1)$ & $18(22.0)$ & $170(28.1)$ & \\
\hline Missing & 67 & 16 & 83 & \\
\hline Total & $590(100.0)$ & $98(100.0)$ & $688(100.0)$ & \\
\hline
\end{tabular}

have important protective effects, and selenium plays an important role in reducing the incidence of oral leukoplakia $(9,14)$. It was reported in Japan (19) that a high level of beta-carotene was associated with a low risk of oral leukoplakia. Beta-carotene-rich vegetables such as broccoli, carrots and peppers (capsicums) or green leafy vegetables appear to provide greater protection than vegetables lacking $\beta$-carotene.

In the present study, as most subjects consumed large quantities of starchy vegetables, it was decided to segregate $\beta$-carotene-rich vegetables and fruits as a subgroup. Statistically significant protective effects for occurrence of OPMD and leukoplakia were observed with high intakes of $\beta$-carotene-containing fruits and vegetables, with a crude OR of 0.50 . However, this protective effect was attenuated when adjusted for confounding factors: the protective effects of certain foods may not be exhibited in a population in which more than one-third of subjects are under-nourished. Consistent with this, bivariate analysis indicated that low BMI $(<18.5)$ was associated with increased risk of OPMD. Similar results have been reported in the pooled analysis of 15 case-control studies from the INHANCE consortium: low BMI, smoking and alcohol consumption increase ORs for head and neck cancer and ORs are reduced in healthy weight, overweight and obese categories (43). Study conducted in Trivandrum city, Kerala, India also reported similar results for BMI and risk of leukoplakia (10).

Based on the evidence that antioxidants in the diet may provide protection against oral cancer, extensive studies from the MD Anderson Cancer Centre in the USA are progressively identifying the most effective combinations of antioxidant supplements of value in promoting the regression of OPMD and the prevention of recurrences and second primary neoplasms in subjects with head and neck cancer. It has to be recognized, however, that these agents do not always prevent the progression of an OPMD to overt cancer $(44,45)$.

Green tea has been shown to reduce oral cancer risk by close to $60 \%$ (for those drinking $>5$ cups/day) and $35 \%$ 
(for those drinking 1-2 cup/day) (46). Further, a recent Phase II trial of green tea supplements promoted regression of OPMD (47, 48). Historically, Sri Lankan populations have consumed large quantities of, predominantly black, tea, but this habit is now decreasing. In the present study, the number of cups of tea consumed per day was small, so it is not surprising that no significant protective effects could be demonstrated. The protective effect of tea could also be masked by the prevailing under-nourishment in the population under study here, and the quality of the tea may be poor in this predominantly low socioeconomic population. Cheap, adulterated tea is commonly found in local markets. The present study shows that alcohol drinkers consumed fewer cups of tea and fewer portions of fruit and vegetables than teetotallers, and tended to frequently miss dinner, compounding their risks of disease.

Studies of this nature are often subjected to information bias as the measurement of consumption of fruit and vegetables was based on self-reported data. People tend alter their food habits as it is requested. This could have been overcome by the biological assessment, which is limited applicability in the community based study.

A recent study conducted in Italy has shown that diets rich in animal products were associated with an increased risk of oral/pharyngeal cancers, and a protective effect was revealed with diets rich in starch, vitamin and fibre and unsaturated fat (49). The Authors concluded that the evidence for any association with diet and oral cancer remains weak and any clinical significance remains limited (49).

Consumption of fruits, vegetables and tea by these rural Sri Lankans is clearly inadequate. The WHO recommends 5 portions (400 g) of fruits and vegetables per day $(15,50)$. We recommend that this population be motivated by culturally sensitive educational programmes to grow and consume more home-grown fruits and vegetables, which could be produced relatively cheaply. Targeted health promotion messages on dietary guidelines on healthy eating to reduce risk of oral cancer need to be devised.

\section{References}

1. Warnakulasuriya S, Johnson NW, van der Waal I. Nomenclature and classification of potentially malignant disorders of the oral mucosa. J Oral Pathol Med 2007; 36: 575-80.

2. Napier SS, Speight PM. Natural history of potentially malignant oral lesions and conditions: an overview of the literature. J Oral Pathol Med 2008; 37: 1-10.

3. Chung CH, Yang YH, Wang TY, Shieh TY, Warnakulasuriya $\mathrm{S}$. Oral precancerous disorders associated with areca quid chewing, smoking, and alcohol drinking in Southern Taiwan. J Oral Pathol Med 2005; 34: 460-6.

4. Thomas SJ, Harris R, Ness AR, et al. Betel quid not containing tobacco and oral leukoplakia: a report on a cross-sectional study in Papua New Guinea and a meta-analysis of current evidence. Int J Cancer 2008; 123: 1871-6.

5. Warnakulasuriya KA, Ekanayake AN, Sivayoham S, et al. Utilization of primary health care workers for early detection of oral cancer and precancer cases in Sri Lanka. Bull World Health Organ 1984; 62: 243-50.

6. Stewart BW, Kleihues P, Stewart Bernard W, Paul K. The cause of cancer in world cancer report. Lyon, France: IARC Press, 2003.
7. Key TJ, Schatzkin A, Willett WC, Allen NE, Spencer EA, Travis RC. Diet, nutrition and the prevention of cancer. Public Health Nutrition 2004; 7(1A): 187-200.

8. Llewellyn CD, Linklater K, Bell J, Johnson NW, Warnakulasuriya $\mathrm{S}$. An analysis of risk factors for oral cancer in young people: a case-control study. Oral Oncol 2004; 40: 304 13.

9. Nagao T, Warnakulasuriya S, Gelbier S, Yuasa H, Tsuboi S, Nakagaki H. Oral pre-cancer and the associated risk factors among industrial workers in Japan's overseas enterprises in the UK. J Oral Pathol Med 2003; 32: 257-64.

10. Hashibe M, Sankaranarayanan R, Thomas G, et al. Alcohol drinking, body mass index and the risk of oral leukoplakia in an Indian population. Int J Cancer 2000; 88: 129-34.

11. Schwartz J, Shklar G. Regression of experimental oral carcinomas by local injection of beta -carotene and canthaxanthin. Nutr Cancer 1988; 11: 35-40.

12. Schwartz JL, Shklar G, Flynn E, Trickler D. The administration of beta carotene to prevent and regress oral carcinoma in the hamster cheek pouch and the associated enhancement of the immune response. Adv Exp Med Biol 1990; 262: 77-93.

13. Shklar G, Schwartz JL, Trickler DP, Reid S. Prevention of experimental cancer and immunostimulation by vitamin $\mathrm{E}$ (immunosurveillance). J Oral Pathol Med 1990; 19: 60-4.

14. Sankaranarayanan R, Mathew B, Varghese C, et al. Chemoprevention of oral leukoplakia with vitamin A and beta carotene: an assessment. Oral Oncol 1997; 33: 231-6.

15. Warnakulasuriya S. Food, nutrition and oral cancer. Food constituents and oral health. Wilson, M, ed. Oxford: Woodhead Publishing Limited, 2009; 273-95

16. Machlin LJ, Bendich A. Free radical tissue damage: protective role of antioxidant nutrients. FASEB J 1987; 1: 441-5.

17. Hennekens $\mathrm{CH}$, Stampfer MJ, Willett W. Micronutrients and cancer chemoprevention. Cancer Detect Prev 1984; 7: 14758.

18. Pavia M, Pileggi C, Nobile CG, Angelillo IF. Association between fruit and vegetable consumption and oral cancer: a meta-analysis of observational studies. Am J Clin Nutr 2006; 83: $1126-34$.

19. Nagao T, Ikeda N, Warnakulasuriya $S$, et al. Serum antioxidant micronutrients and the risk of oral leukoplakia among Japanese. Oral Oncol 2000; 36: 466-70.

20. Maher R, Aga P, Johnson NW, Sankaranarayanan R, Warnakulasuriya S. Evaluation of multiple micronutrient supplementation in the management of oral submucous fibrosis in Karachi, Pakistan. Nutr Cancer 1997; 27: 41-7.

21. Imai K, Suga K, Nakachi K. Cancer-preventive effects of drinking green tea among a Japanese population. Prev Med 1997; 26: 769-75.

22. Johnson IT. Green tea and cancer. Lancet Oncol 2010; 11: 519-20.

23. Yang CS, Wang X. Green tea and cancer prevention. Nutr Cancer 2010; 62: 931-7.

24. Schuck AG, Ausubel MB, Zuckerbraun HL, Babich H. Theaflavin-3,3'-digallate, a component of black tea: an inducer of oxidative stress and apoptosis. Toxicol In Vitro 2008; 22: 598-609.

25. Babich H, Gottesman RT, Liebling EJ, Schuck AG. Theaflavin-3-gallate and theaflavin-3'-gallate, polyphenols in black tea with prooxidant properties. Basic Clin Pharmacol Toxicol 2008; 103: 66-74.

26. Letchoumy PV, Mohan KV, Prathiba D, Hara Y, Nagini S. Comparative evaluation of antiproliferative, antiangiogenic and apoptosis inducing potential of black tea polyphenols in the hamster buccal pouch carcinogenesis model. J Carcinog 2007; 6: 19. 
27. Letchoumy PV, Subapriya R, Nagini S, Abraham SK. Protective effect of black tea polyphenols against 7,12dimethylbenz[a]anthracene-induced genotoxicity and oxidative stress during hamster buccal pouch carcinogenesis. Toxicol Mech Methods 2007; 17: 93-100.

28. Lampe JW. Spicing up a vegetarian diet: chemopreventive effects of phytochemicals. Am J Clin Nutr 2003; 78(3 Suppl): 579S-83S

29. Amarasinghe HK, Usgodaarachchi US, Johnson NW, Lalloo R, Warnakulasuriya S. Public awareness of oral cancer, of oral potentially malignant disorders and of their risk factors in some rural populations in Sri Lanka. Community Dent Oral Epidemiol 2010; 38: 540-8.

30. Amarasinghe HK, Johnson NW, Lalloo R, Kumaraarachchi M, Warnakulasuriya S. Derivation and validation of a risk-factor model for detection of oral potentially malignant disorders in populations with high prevalence. Br J Cancer 2010; 103: 303-9.

31. Morse DE, Poster WJ, Cleveland D, et al. Smoking and drinking in relation to oral cancer and oral epithelial dysplasia. Cancer Causes Control 2007; 18: 919-29.

32. Amarasinghe HK, Usgodaarachchi US, Johnson NW, Lalloo $\mathrm{R}$, Warnakulasuriya S. Betel-quid chewing with or without tobacco is a major risk factor for oral potentially malignant disorders in Sri Lanka: a case-control study. Oral Oncol 2010; 46: 297-301.

33. Zain RB, Ikeda N, Gupta PC, et al. Oral mucosal lesions associated with betel quid, areca nut and tobacco chewing habits: consensus from a workshop held in Kuala Lumpur, Malaysia, November 25-27, 1996. J Oral Pathol Med 1999; 28: $1-4$.

34. Axell T, Rundquist L. Oral lichen planus- a demographic study. Community Dent Oral Epidemiol 1987; 15: 52-6.

35. Hsue SS, Wang WC, Chen CH, Lin CC, Chen YK, Lin LM. Malignant transformation in 1458 patients with potentially malignant oral mucosal disorders: a follow-up study based in a Taiwanese hospital. J Oral Pathol Med 2007; 36: 25-9.

36. Zurriaga O, Martinez-Beneito MA, Abellan JJ, Carda C. Assessing the social class of children from parental information to study possible social inequalities in health outcomes. Ann Epidemiol 2004; 14: 378-84.

37. Ministry of Health Sri Lanka. Food based dietary guidelines. Colombo: Ministry of Health Sri Lanka, 2002.

38. Hector Kobbakaduwa Agricultural Research Centre. Low cost food recipes of Sri Lanka, Sri Lanka: Hector Kobbakaduwa

7 Agricultural Research Centre, 1995.

39. van Staveren WA, de Boer JO, Burema J. Validity and reproducibility of a dietary history method estimating the usual food intake during one month. Am J Clin Nutr 1985; 42: $554-9$.
40. Franceschi S, Favero A, Conti E, et al. Food groups, oils and butter, and cancer of the oral cavity and pharynx. Br J Cancer 1999; 80: 614-20.

41. American Institute for Cancer Research. Food, nutrition, physical activity and the prevention of cancer: a global perspective, . Available at: http://www.dietandcancerreport. org/ (accessed on 15 January, 2010).

42. Gupta PC, Hebert JR, Bhonsle RB, Sinor PN, Mehta H, Mehta FS. Dietary factors in oral leukoplakia and submucous fibrosis in a population-based case control study in Gujarat, India. Oral Dis 1998; 4: 200-6.

43. Lubin JH, Muscat J, Gaudet MM, et al. An examination of male and female odds ratios by BMI, cigarette smoking, and alcohol consumption for cancers of the oral cavity, pharynx, and larynx in pooled data from 15 case-control studies. Cancer Causes Control 2011; 22: 1217-31.

44. William WN, Lee JJ, Lippman SM, et al. High-dose fenretinide in oral leukoplakia. Cancer Prev Res (Phila Pa) 2009; 2: 22-6.

45. Papadimitrakopoulou VA, Lee JJ, William WN, et al. Randomized trial of 13-cis retinoic acid compared with retinyl palmitate with or without beta-carotene in oral premalignancy. J Clin Oncol 2009; 27: 599-604.

46. Ide R, Fujino Y, Hoshiyama Y, et al. A prospective study of green tea consumption and oral cancer incidence in Japan. Ann Epidemiol 2007; 17: 821-6.

47. Tsao AS, Liu D, Martin J, et al. Phase II randomized, placebocontrolled trial of green tea extract in patients with high-risk oral premalignant lesions. Cancer Prev Res (Phila) 2009; 2: 931-41.

48. Tavani A, Bertuzzi M, Talamini R, et al. Coffee and tea intake and risk of oral, pharyngeal and oesophageal cancer. Oral Oncol 2003; 39: 695-700.

49. Edefonti V, Bravi F, La Vecchia C, et al. Nutrient-based dietary patterns and the risk of oral and pharyngeal cancer. Oral Oncol 2010; 46: 343-8.

50. World Health Organization. Diet, Nutrition and the Prevention of Chronic Disease, Report of a joint FAO/WHO Expert consultation, Geneva: World Health Organization, 2003. (WHO Technical Report Series, No 916).

\section{Acknowledgements}

We acknowledge the financial support of the WHO and the contribution made by the National Director of Oral Health, Dr Jayasundara Bandara. We are indebted to study participants and their families, and to staff of the MOH Bulathkohupitiya and MOH Ayagama Districts. We thank Dr (Mrs) S.R.H.P Gunawardana and Mrs R.M.L.R Tilakerathne for scientific contributions. 


\section{Author Query Form}

\section{Journal: $\quad$ JOP}

Article: $\quad 12067$

Dear Author,

During the copy-editing of your paper, the following queries arose. Please respond to these by marking up your proofs with the necessary changes/additions. Please write your answers on the query sheet if there is insufficient space on the page proofs. Please write clearly and follow the conventions shown on the attached corrections sheet. If returning the proof by fax do not write too close to the paper's edge. Please remember that illegible mark-ups may delay publication.

Many thanks for your assistance.

\begin{tabular}{|l|l|l|}
\hline Query reference & Query & Remarks \\
\hline 1 & $\begin{array}{l}\text { AUTHOR: A running head short title was not supplied; please check if this } \\
\text { one is suitable and, if not, please supply a short title of up to 40 characters } \\
\text { that can be used instead. }\end{array}$ & \\
\hline 2 & AUTHOR: Please provide city and country name for affiliation 6. & \\
\hline 3 & AUTHOR: Please check that authors and their affiliations are correct. & \\
\hline 5 & $\begin{array}{l}\text { AUTHOR: Please check and provide full postal address, telephone and fax } \\
\text { number for corresponding author. }\end{array}$ & \\
\hline 6 & $\begin{array}{l}\text { AUTHOR:Please check whether the edits made in the sentence "The global } \\
\text { ․ Papua New Guinea, 11.7\% (4)" are OK. }\end{array}$ & \\
\hline 7 & $\begin{array}{l}\text { AUTHOR: References [3] and [36] are identical. Hence, reference [36] is } \\
\text { deleted and rest of the references are renumbered. Please check. }\end{array}$ & \\
\hline
\end{tabular}


Required software to e-Annotate PDFs: Adobe Acrobat Professional or Adobe Reader (version 7.0 or above). (Note that this document uses screenshots from Adobe Reader $\mathbf{X}$ )

The latest version of Acrobat Reader can be downloaded for free at: http://get.adobe.com/uk/readerl

Once you have Acrobat Reader open on your computer, click on the Comment tab at the right of the toolbar:

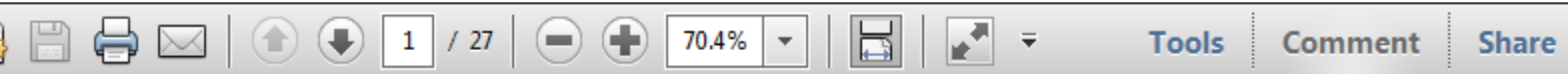

This will open up a panel down the right side of the document. The majority of tools you will use for annotating your proof will be in the Annotations section, pictured opposite. We've picked out some of these tools below:

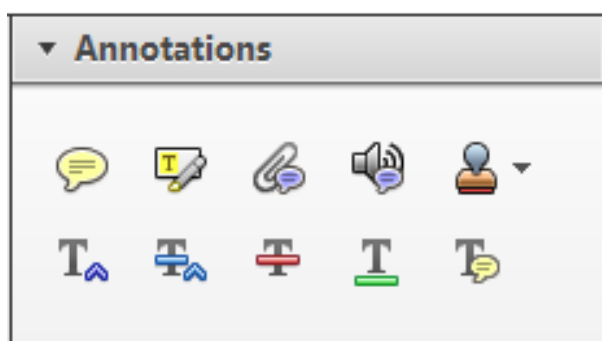

1. Replace (Ins) Tool - for replacing text.

Strikes a line through text and opens up a text box where replacement text can be entered.

How to use it

- Highlight a word or sentence

- Click on the Replace (Ins) icon in the Annotations section.

- Type the replacement text into the blue box that appears.

Idard tramework for the analysis of $\mathrm{m}$ icy-Nevertheless, it also led to exog،

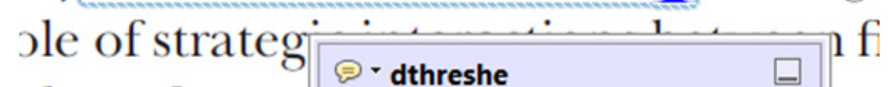
aber of comp 08/06/2011 15:58:17 is that the $\mathrm{s} 1 \overline{\text {, which led }}$ of nain compo: be level, are exc nc

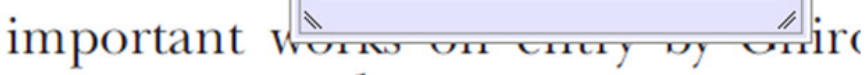
M henceforth) ${ }^{1}$ we snen the "hlark $\mathrm{h}$

3. Add note to text Tool - for highlighting a section to be changed to bold or italic.

Th Highlights text in yellow and opens up a text box where comments can be entered.

\section{How to use it}

- Highlight the relevant section of text.

- Click on the Add note to text icon in the Annotations section.

- Type instruction on what should be changed regarding the text into the yellow box that appears

namic responses of mark ups ent with the VAR evidence

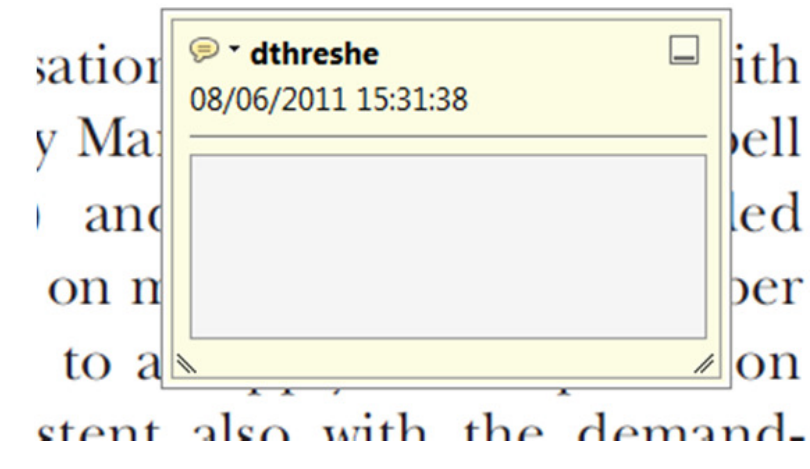

2. Strikethrough (Del) Tool - for deleting text.

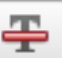

Strikes a red line through text that is to be deleted.

How to use it

- Highlight a word or sentence.

- Click on the Strikethrough (Del) icon in the Annotations section.

there is no room tor extra prohts al s ups are zero and the number of ret) values are not determined by Blanchard and Kiyotaki (1987), sfect competition in general equilil ts of aggregate demand and supply lassical framework assuming mono sen on evorenous nimher of firms

4. Add sticky note Tool - for making notes at specific points in the text.

Marks a point in the proof where a comment needs to be highlighted.

How to use it

- Click on the Add sticky note icon in the Annotations section.

- Click at the point in the proof where the comment should be inserted.

- Type the comment into the yellow box that appears.

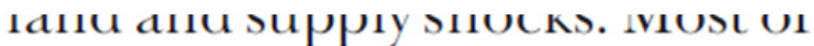

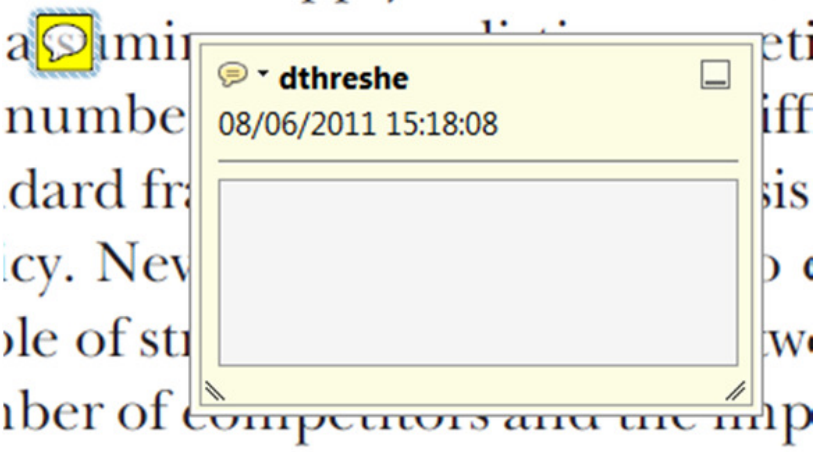

is that the structure of the sects. 
5. Attach File Tool - for inserting large amounts of text or replacement figures.

Inserts an icon linking to the attached file in the appropriate pace in the text.

How to use it

- Click on the Attach File icon in the Annotations section.

- Click on the proof to where you'd like the attached file to be linked.

- Select the file to be attached from your computer or network.

- Select the colour and type of icon that will appear in the proof. Click OK.

E N D

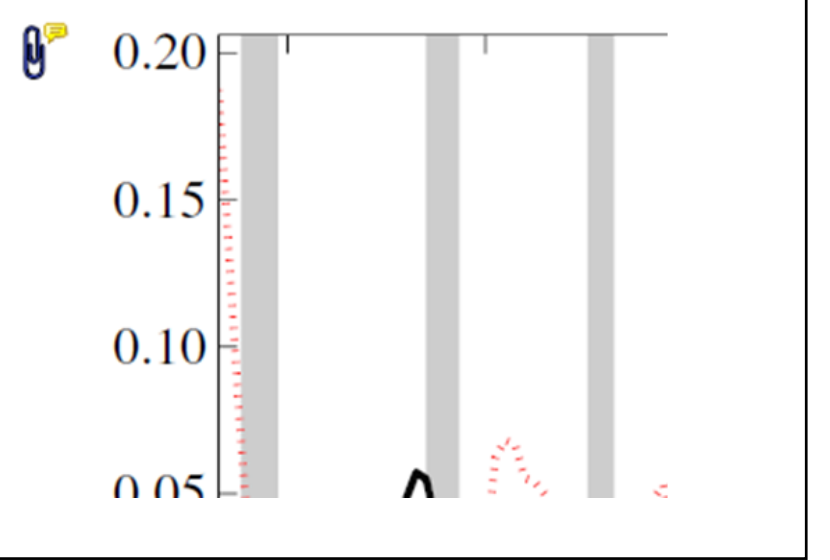

6. Add stamp Tool - for approving a proof if no corrections are required.

- Inserts a selected stamp onto an appropriate place in the proof

\section{How to use it}

- Click on the Add stamp icon in the Annotations section.

- Select the stamp you want to use. (The Approved stamp is usually available directly in the menu that appears).

- Click on the proof where you'd like the stamp to appear. (Where a proof is to be approved as it is, this would normally be on the first page).

of the Dusiness cycie, starting with the on perfect competition, constant ret

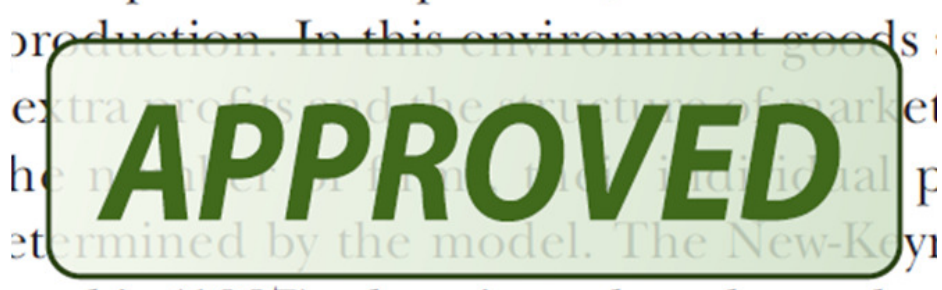
otaki (1987), has introduced produc general equilibrium models with nomin:

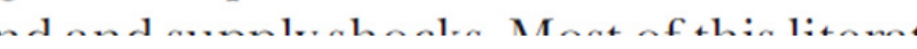

- Drawing Markups

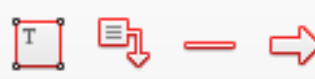

$0 \square \sqrt{ } \rightarrow 0$

\section{How to use it}

- Click on one of the shapes in the Drawing Markups section.

- Click on the proof at the relevant point and draw the selected shape with the cursor.

- To add a comment to the drawn shape, move the cursor over the shape until an arrowhead appears.

- Double click on the shape and type any text in the red box that appears.
7. Drawing Markups Tools - for drawing shapes, lines and freeform annotations on proofs and commenting on these marks.

Allows shapes, lines and freeform annotations to be drawn on proofs and for comment to be made on these marks.

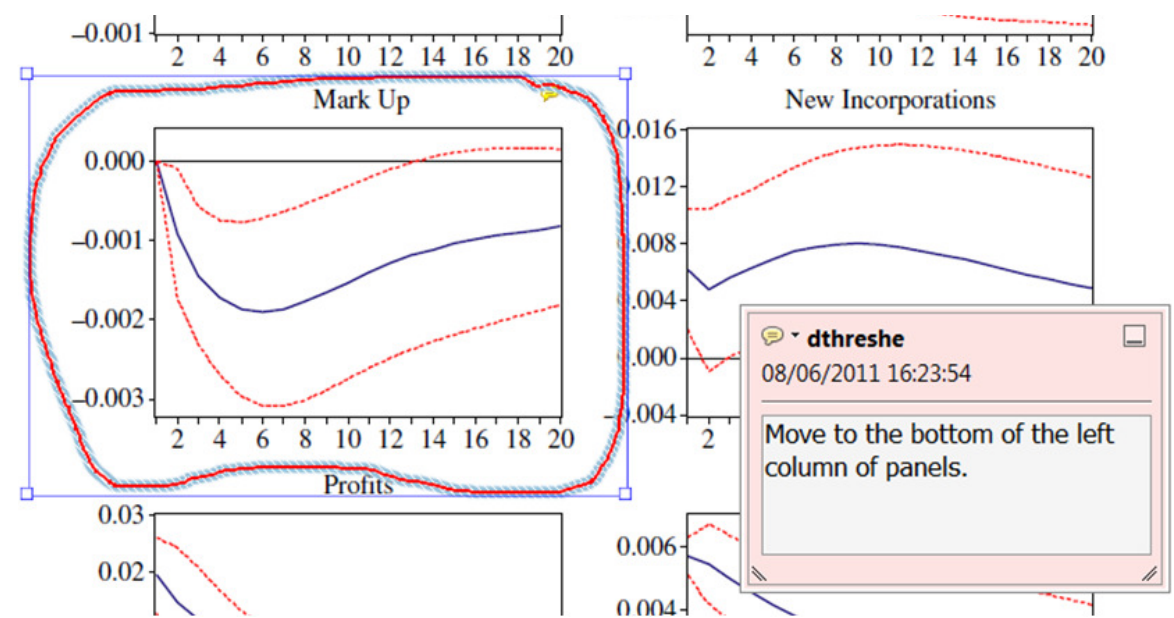

For further information on how to annotate proofs, click on the Help menu to reveal a list of further options:

\begin{tabular}{|l|l|l|l|l|l|l|}
\hline File ecoj_2384_CrxRev2_EV_19-Jul-10.pdf - Adobe Reader & Edit View Window \\
\hline
\end{tabular}

